\title{
Positive Regulation of Serotonin Release
}

National Cancer Institute

\section{Source}

National Cancer Institute. Positive Regulation of Serotonin Release. NCI Thesaurus. Code C41533.

Any process in which the monoamine neurotransmitter serotonin is released or retained in the synaptic cleft, resulting in induced or sustained neurotransmission. Serotonin release can be upregulated in the presence of the empathogen MDMA. Monoamine oxidase inhibitors similarly increase steady state levels of serotonin in the brain by reducing its degradation within synapses. This process is involved in numerous functions, including regulation of mood, appetite, sleep, muscle contraction, and some cog nitive functions including memory and learning. 